\title{
Trimmed down Chiron pitches cancer genomics
}

One of the more unlikely events at the 6th Annual BioPartnering Europe meeting, held in London in late October, was the unveiling of a corporate cancer genomics program that has led already to the filing of patents on several thousand novel cancer-associated genes. What was most surprising about the announcement, however, was not its nature but its source. The company involved, Chiron (Emeryville, CA), is consistently one of biotechnology's top five earners, but was until recently a company that had fallen out of favor with investors and stock analysts. Coming on the back of wholesale business divestment and refocusing, the company's emerging R\&D programs are helping reinvigorate investor interest.

According to Abla Creasey, Chiron's vice president of product discovery and development, the company made its cancer genomics announcement in October because it had reached a stage in the program where it wanted to involve pharmaceutical company partners in going beyond gene identification and toward the development of small molecule lead compounds. "Chiron does have small molecule programs but we do not have the resources to do this alone," she says. The partnerships would aim to use "the Chiron model" of shared risk and shared benefit to explore the roles of the novel genes and, in particular, the 500 differentially expressed loci. Creasy maintains that Chiron's program goes much deeper than most other genomics efforts. Each tissue sample the company examines is used to generate expression libraries of around 400,000 clones. "This means we can identify the least abundant genes." she says. "In eight months, we have found 6,700 novel genes, many of them not available as ESTs [expressed sequence tags]." Furthermore, drawing on its resources in gene therapy, Chiron has been able to start to validate some of the new targets in animal and cell models.

The possibility of a hook-up with a major collaborator would bring Chiron full circle. At the start of 1998, a number of analysts had characterized Chiron as having huge potential but lacking in direction. Its franchise in oncology, established through its development and marketing of Proleukin (recombinant interleukin-2) for the treatment of metastatic renal cell carcinoma and metastatic melanoma, represented a somewhat underexploited potential. Until just over a year ago, Chiron had appeared to be developing by accretion of commercially unassociated businesses, many of which either generated low revenues or low margins. For the financial year ending December 31, its operating income on revenues of $\$ 1.16$ billion was only $\$ 50$ million $(4.3 \%)$. In addition to selfgenerated products such as Proleukin, Chiron had made a number of acquisitions. For instance, it spent $\$ 120$ million buying $49 \%$ of the human vaccine business of the Hoechst (Frankfurt) subsidiary, Behringwerke, in July 1996 and \$95 million buying the opthalmic surgical products division of Johnson \& Johnson (New Brunswick, NJ) in March 1995.

But from the end of 1997, Chiron set out on a program of divestment. In December 1997, it sold its quality-control diagnostics business, including manufacturing facilities in Irvine, California, to Bio-Rad Laboratories (Hercules, CA) for an undisclosed sum. It also completed the sale of Chiron Vision (a business that encompassed the 1995 J\&J acquisition) to Bausch \& Lomb for $\$ 300$ million. The arrival in March of this year of former Glaxo Wellcome (London) chief operating officer Sean Lance as Chiron's chief executive officer has further accelerated the company's refocusing pro- gram. In September, the biggest divestment yet occurred when Bayer (Leverkusen, Germany) agreed to buy Chiron's in vitro diagnostics business for $\$ 1.1$ billion, a move that was so well received by the financial markets that it propelled Chiron's stock price from a 1998 low of around $\$ 14$ at the beginning of September to $\$ 20-21$ by the end of the month.

The share price received a further boost on the release of the company's 9-month figures in October, which showed operating income of $\$ 66.8$ million, not only an absolute increase over 1997 income but also a significant increase as a proportion of revenue- $13 \%$ compared with $4.3 \%$ for 1997 . In less than a year, Chiron had become a leaner, less convoluted, more profitable company.

The divestments are not yet complete: The vaccines division is another divestment candidate, principally because although Chiron has some interesting vaccine technology, it is only among the market leaders in territories such as Italy and Germany.

John Hodgson

\section{Taiwan promotes biotechnology}

In what some see as the first realistic initiative to create an infrastructure for its fledgling biotechnology industry, Taiwan has launched BioTrust International Corp., a project initially focused on making Taiwan self-sufficient in processing blood plasma products. Although the Taiwanese government is keen to promote and develop biotechnology, some researchers think its programs are overambitious for what is still a preliminary industry lacking in adequate technology and expertise.

BioTrust (Taipei) was established in October 1998 by the Academia Sinica (Taipei) and the Chinese Blood Service Foundation (CBSF; Taipei), a private nonprofit organization responsible for collecting blood and plasma in Taiwan. The Taiwanese government hopes the new project will remedy Taiwan's dependency on foreign imports for plasma products-something that currently costs the nation up to TW $\$ 1306$ (US\$40 million) each year.

BioTrust, which is affiliated with YungShin Pharmaceutical (Taipei), a major drug manufacturer in Taiwan, will operate as a collaborative venture with the Scottish Blood Transfusion Service (SBTS; Edinburgh), and will be supported by the Taiwanese Department of Health (Taipei), the National Health Research Institute (Taipei), and the Ministry of Economic Affairs (Taipei). The project will have an initial annual budget of TW\$653 million (US\$20 million), which is expected to increase to TW\$1306-1632 million (US $\$ 40-50$ million) a year in 2 to 3 years.

At first, plasma collected in Taiwan will be processed in Scotland into such products as albumin, immunoglobulin G, and highly purified factor VIII, according to CBSF. But the new plasma fractionation facility, which will be able to fractionate $300,000 \mathrm{~L}$ of plasma per year, will be completed in Taipei in 2001. That project will receive technical assistance from Human Plasma Product Services (HPPS; Paris), a French company specializing in industrial plasma fractionation.

As well as allowing self-sufficiency in processing plasma products, it is hoped that 